\title{
Hypoxic Hepatitis: A Review and Clinical Update
}

\author{
Najeff Waseem ${ }^{1,2}$ and Po-Hung Chen ${ }^{1 *}$ \\ ${ }^{1}$ Division of Gastroenterology \& Hepatology, Department of Medicine, Johns Hopkins University School of Medicine, \\ Baltimore, MD, USA; ${ }^{2}$ George Washington School of Medicine and Health Sciences, Washington, DC, USA
}

\begin{abstract}
Hypoxic hepatitis $(\mathrm{HH})$, also known as ischemic hepatitis or shock liver, is characterized by a massive, rapid rise in serum aminotransferases resulting from reduced oxygen delivery to the liver. The most common predisposing condition is cardiac failure, followed by circulatory failure as occurs in septic shock and respiratory failure. $\mathrm{HH}$ does, however, occur in the absence of a documented hypotensive event or shock state in $50 \%$ of patients. In intensive care units, the incidence of $\mathrm{HH}$ is near $2.5 \%$, but has been reported as high as $10 \%$ in some studies. The pathophysiology is multifactorial, but often involves hepatic congestion from right heart failure along with reduced hepatic blood flow, total body hypoxemia, reduced oxygen uptake by hepatocytes or reperfusion injury following ischemia. The diagnosis is primarily clinical, and typically does not require liver biopsy. The definitive treatment of $\mathrm{HH}$ involves correction of the underlying disease state, but successful management includes monitoring for the potential complications such as hypoglycemia, hyperglycemia, hyperammonemia and hepatopulmonary syndrome. Prognosis of $\mathrm{HH}$ remains poor, especially for cases in which there was a delay in diagnosis. The in-hospital mortality rate is $>50 \%$, and the most frequent cause of death is the predisposing condition and not the liver injury itself.
\end{abstract}

(C) 2016 The Second Affiliated Hospital of Chongqing Medical University. Published by XIA \& HE Publishing Inc. All rights reserved.

\section{Introduction}

Hepatic necrosis around the central veins, a condition now known as centrilobular necrosis, was first described as early as 1901 based upon a series of autopsies in Boston reported by F.B. Mallory. ${ }^{1}$ Later, Bynum et al. ${ }^{2}$ noted the same pattern of necrosis in cardiac failure patients suffering from dramatic rises in serum aminotransferase level. The condition was termed as "ischemic hepatitis," and since then it has also been referred to in the literature as "shock liver" and now, most frequently, as "hypoxic hepatitis" $(\mathrm{HH}){ }^{3-5}$

Keywords: Ischemia; Hypoxia; Hepatitis; Liver injury.

Abbreviations: $\mathrm{HH}$, hypoxic hepatitis; ICG, indocyanine green; ICU, intensive care unit; INR, international normalized ratio.

Received: 20 May 2016; Revised: 14 August 2016; Accepted: 18 August 2016 DOI: $10.14218 / \mathrm{JCTH} .2016 .00022$.

*Correspondence to: Po-Hung Chen, Division of Gastroenterology \& Hepatology, Department of Medicine, Johns Hopkins University School of Medicine, 4940 Eastern Avenue, Suite A-505, Baltimore, MD 21224, USA. Tel: +1-410-550-1793, Fax: +1-410-550-7861, E-mail: pchen37@jhmi.edu
The current diagnosis of $\mathrm{HH}$ generally relies on three criteria: a clinical setting resulting in reduced oxygen delivery or utilization by the liver, a significant and often transient increase in serum aminotransferase level, and exclusion of other potential causes of liver injury like drug or viral induced hepatitis. The clinical states that are defined as predisposing to $\mathrm{HH}$ include, most commonly, acute cardiac failure, toxicshock states and respiratory failure $;^{3-6}$ however, the condition can occur even without the patient being in shock ${ }^{7}$ or without a documented hypotensive event. ${ }^{8}$ As such, the majority of cases of $\mathrm{HH}$ are diagnosed in the intensive care unit (ICU). For diagnosis, Henrion et al. ${ }^{3}$ suggested the use of serum aminotransferase level at 20 times the upper limit of normal, but others have used a lower cutoff, ranging from 2.5 to 10 times the upper limit of normal. ${ }^{9-13}$ When all three criteria are met, however, the diagnosis of $\mathrm{HH}$ can be assumed without the use of liver biopsy, but when in doubt biopsy can provide a definitive diagnosis. ${ }^{14}$

\section{Epidemiology}

$\mathrm{HH}$ has become increasingly recognized in ICUs, where it is now one of the leading causes of dramatic rises in serum aminotransferase levels. ${ }^{15,16}$ In a recent meta-analysis of 1782 cases, Tapper et al. ${ }^{8}$ identified the incidence of $\mathrm{HH}$ to be 2 in every 1000 patients for all levels of hospital care, but in ICUs alone the pooled incidence is higher, accounting for 2.5 out of every 100 patients. This finding is consistent with previously reported incidences of $1-2.5 \%$ in the ICU. ${ }^{3-6,12}$ In patients presenting to the ICU with pre-existing increased serum aminotransferase levels at 10 times above normal, the incidence of $\mathrm{HH}$ is reportedly as high as 4 out of every 10 admissions. $^{8}$ It is possible that these pooled incidences are too conservative, as the diagnosis is sometimes overlooked clinically ${ }^{7}$ indeed, some estimates have placed the incidence closer to $10 \%$ in ICUs. ${ }^{17}$

\section{Etiology}

$\mathrm{HH}$ is frequently multifactorial, and one study found more than one underlying risk factor in nearly three-quarters of the patients analyzed. ${ }^{5}$ The conditions of cardiac failure resulting in a low output state, sepsis, and respiratory failure together account for $>90 \%$ of cases, ${ }^{7}$ but there are a variety of other documented causes. Once thought to be prerequisites for diagnosis, documented hypotensive events and shock states both have now been shown to occur in only about $50 \%$ of patients with $\mathrm{HH} .^{7,8}$

The majority of cases described in the literature identify cardiac failure underlying $\mathrm{HH}$, ranging from $39-70 \% .{ }^{3-6,18}$ In the aforementioned recent meta-analysis, as high as $78 \%$ of 
$\mathrm{HH}$ cases were found to be caused by an acute cardiac event. ${ }^{8}$ Patients are especially at risk when there is passive congestion of the liver related to right-sided heart failure, ${ }^{19-21}$ with some literature asserting that the passive congestion may be a necessary prerequisite for the development of $\mathrm{HH}^{22}$

Most prevalent among the other risk factors was the condition of septic shock. In one study, septic shock was identified in $32 \%$ of patients suffering from $\mathrm{HH}$ and was the leading cause of death. ${ }^{5}$ Other studies have identified sepsis in $6 \%{ }^{22}$ to $33 \%{ }^{6}$ of the patients with $\mathrm{HH}$, with a pooled proportion of about $23 \% .^{8}$ Respiratory failure has also been noted as a common predisposing condition, reportedly occurring in nearly $15 \%$ of patients ${ }^{7}$ and ranging from as low as $7 \% \%^{6}$ to as high as $34 \%^{23}$ in the studies. Other documented preconditions include hypovolemic shock, anemia, extensive burns and sleep apnea. ${ }^{5,23-25}$

Pre-existing liver pathologies, especially cirrhosis, can also lead to poorer outcomes in $\mathrm{HH}^{5,9}$ Cirrhotic livers have portosystemic shunting and impaired functional blood flow, ${ }^{26}$ which thereby exacerbate the hypoxic damage suffered from a shock state or upon respiratory failure. The association between $\mathrm{HH}$ and other chronic liver diseases, such as viral hepatitis or alcoholic liver disease, has not yet been explicitly studied. Nonetheless, given the natural history of chronic hepatitis $B$ and $C$ infections, cases that have progressed to cirrhosis are at increased risk for $\mathrm{HH}$.

\section{Pathophysiology}

Regardless of the underlying etiology, in order to sustain anoxic injury, the normally robust defense mechanisms of the liver must be overcome. The liver is protected from ischemic injury by a dual blood flow system, in which the near $25 \%$ of cardiac output that the liver receives is split between the portal vein and the hepatic artery. ${ }^{27,28}$ In addition, the highly permeable sinusoids of the liver allow for increased oxygen diffusion to the hepatocytes, facilitating oxygen extraction to levels near $90 \%{ }^{29}$ Finally, the liver is normally able to respond to decreases in cardiac blood flow by releasing adenosine and dilating the hepatic vasculature to increase hepatic blood flow. ${ }^{30}$

The pathophysiology of $\mathrm{HH}$ is often multifactorial, as displayed in Figure 1, but the predominating mechanism of damage to the liver can be different depending on the underlying condition. As mentioned previously, passive congestion of the liver related to right-sided heart failure has been the most studied, and is likely the most contributory, of all the pathophysiologic mechanisms. In a case-control study, Seeto et al. ${ }^{22}$ found that underlying heart disease is a major predictor for the development of ischemic hepatitis among patients with at least 15 minutes of documented hypotension; moreover, of these patients, $94 \%$ had right-sided heart failure. These findings were confirmed by Henrion et al. ${ }^{3}$ and Birrer et al. ${ }^{4}$, with both groups demonstrating elevated central venous pressures, reduced delivery of oxygen and reduced hepatic blood flow in patients suffering from $\mathrm{HH}$ caused by cardiac failure. Additionally, Birrer et al. ${ }^{4}$ showed that mean pulmonary capillary wedge pressure and systemic vascular resistance were elevated in all patient groups suffering from $\mathrm{HH}$. Therefore, the combination of pre-existing hepatic congestion and any acute event resulting in reduced hepatic blood flow greatly predisposes the liver to hypoxic injury. ${ }^{19}$
Oxygen delivery is a function of both cardiac output and oxygen saturation. In addition to reduced hepatic blood flow, total body hypoxemia can also result in hypoxic damage to the liver, as evidenced in an exacerbation of chronic respiratory failure. During these times, very low levels of arterial pressure of oxygen (less than $40 \mathrm{mmHg}$ ) serve to predispose the liver to hypoxic damage, as the hypoxemia causes a severe reduction in delivery of oxygen to the hepatocytes. ${ }^{31,32}$ Henrion et al. ${ }^{3}$ and Birrer et al. ${ }^{4}$ reported that their cohorts of patients with respiratory failure and $\mathrm{HH}$ had low average levels of arterial oxygen (34 and $32 \mathrm{mmHg}$ respectively), but also showed elevated central venous pressures in these patients, suggesting an element of hepatic venous congestion.

In septic shock, the proposed mechanism of hypoxic injury is not a failure to deliver oxygen but rather an inability of hepatocytes to utilize oxygen. Splanchnic blood flow is increased in septic shock, ${ }^{33}$ but inflammatory mediators and the release of endotoxin likely reduce the capability of hepatocytes to extract oxygen from blood. ${ }^{34,35}$ When coupled with states of reduced cardiac output, the effect is yet again multiplied, making hypoxic damage to the liver more likely.

While the previously described mechanisms outline how reduced oxygen delivery and utilization lead to hepatocyte necrosis, it has been theorized that the initial lack of oxygen may not be the only source of injury and rather that the hepatocytes suffer damage upon re-oxygenation. Ischemia/ reperfusion injury has been described since the early time of $\mathrm{HH}$ study, ${ }^{36,37}$ but the exact mechanism remains unknown. Detailed discussion of the mechanism that has been proposed is beyond the scope of this review, but it is appropriate to note that it generally includes the formation of reactive oxygen species; the details can be found in various reviews published in the literature. ${ }^{7,23,38}$ Regardless of the exact timing and mechanism of injury, however, the aforementioned pathological pathways all ultimately lead to the same clinical syndrome of $\mathrm{HH}$.

\section{Clinical presentation}

$\mathrm{HH}$ often affects elderly men, with mean reported ages between 64 and 70 years-old, ${ }^{3-6,8}$ who suffer from medical co-morbidities including heart failure or chronic respiratory failure. ${ }^{11}$ Patients presenting to the ICU usually have pre-existing increased serum aminotransferases, ${ }^{3}$ and generally show signs and symptoms of the underlying precondition, such as ankle edema, hepatojugular reflux or shortness of breath as a result of cardiac insufficiency. ${ }^{39}$ Patients can, however, develop right-upper quadrant abdominal pain, hepatomegaly (50\% of patients), ${ }^{3,38}$ or elevated serum bilirubin $>3 \mathrm{mg} / \mathrm{dL}$ ( $36 \%$ of patients). ${ }^{40}$ Sequelae of liver disease, including encephalopathy and hyperammonemia, can also occur; encephalopathy, however, usually results from the predisposing condition such as sepsis or hypoxic injury to the brain, rather than being a direct result of the liver damage. ${ }^{41}$ In addition, both hypoglycemia $^{12}$ and hyperglycemia ${ }^{42}$ have been reported in patients with $\mathrm{HH}$.

Patients with $\mathrm{HH}$ have rapid, transient rises in serum aminotransferase levels (aspartate and alanine aminotransferase) as well as a dramatic rise in lactate dehydrogenase levels. This sharp rise in lactate dehydrogenase can sometimes point to $\mathrm{HH}$ as the cause of liver injury as opposed to viral hepatitis. ${ }^{43}$ These liver enzymes typically peak early in the course of the disease, often within 24 hours, but after 24 to 72 hours the enzyme levels drop to nearly half of their 
Waseem N. et al: Hypoxic hepatitis
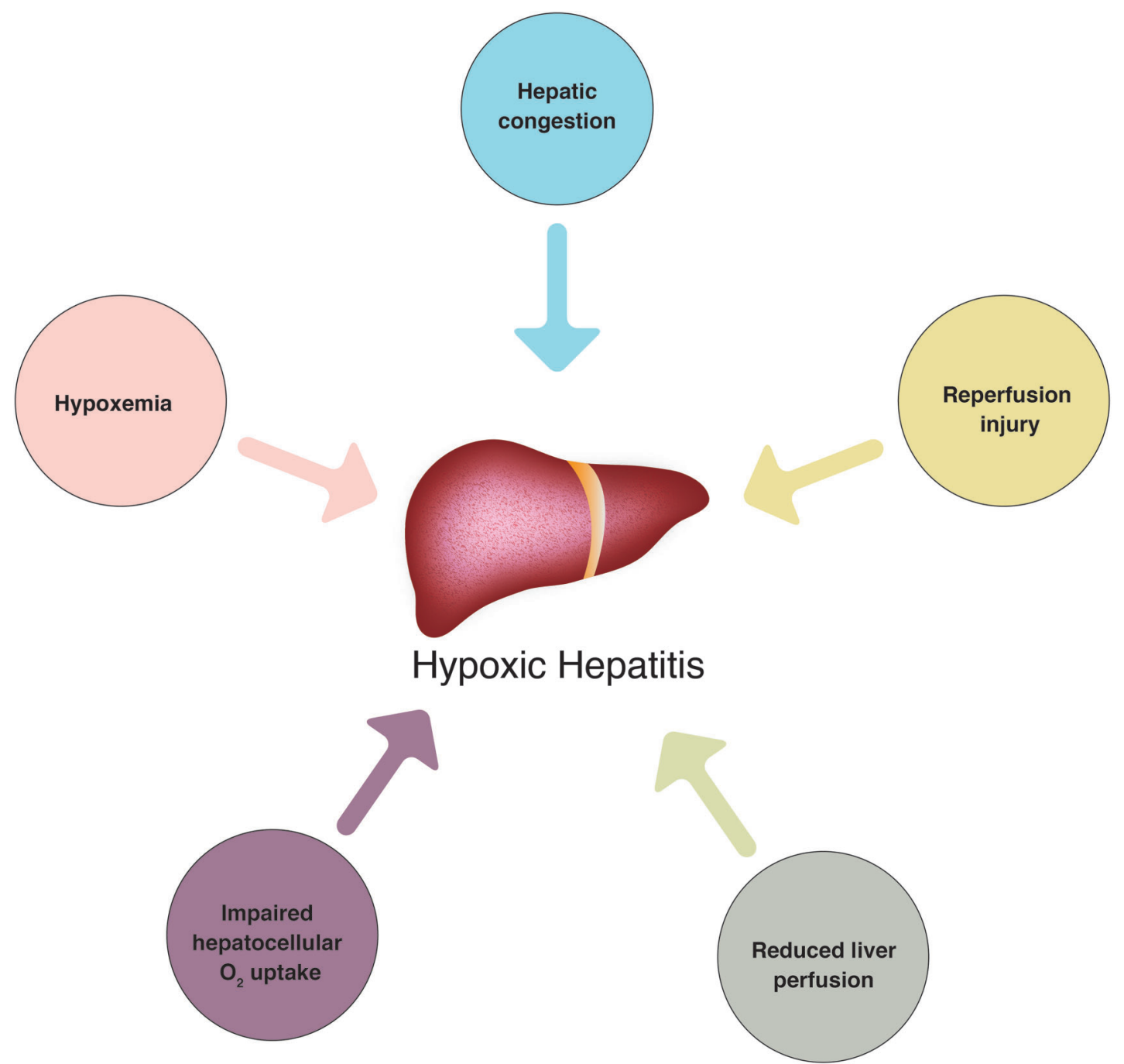

Fig. 1. Multifactorial contributors to hypoxic hepatitis. The pathophysiological mechanisms leading to hypoxic hepatitis are presented. These can occur alone or in concert, depending on the underlying condition.

Abbreviation: $\mathrm{O}_{2}$, oxygen.

peaks, ${ }^{7,23}$ with normalization typically occurring within 1 to 2 weeks. $^{7,23}$

Other abnormal laboratory findings can be found in $\mathrm{HH}$ patients, but they are non-specific and not considered sufficiently reliable for diagnosis. Patients typically have reduced prothrombin activity, and can show increases in serum creatinine $(>2 \mathrm{mg} / \mathrm{dL} \text { in } 65 \% \text { of patients) })^{3,4}$ as well as serum bilirubin ( $>3 \mathrm{mg} / \mathrm{dL}$ in $36 \%$ of patients). ${ }^{40}$ Serum lactate levels can also be elevated, due to impaired hepatic clearance. ${ }^{44}$ Finally, elevations in the international normalized ratio (INR) can occur, with levels $>1.5$ supporting the diagnosis of acute liver failure. ${ }^{45}$

\section{Diagnosis}

The diagnosis of $\mathrm{HH}$ is largely clinical, using the three widely accepted criteria listed in Table $1 .^{3}$ The differential diagnosis of liver conditions leading to massively and rapidly elevated liver enzymes is limited, and $\mathrm{HH}$ is one of the leading causes
(Table 2) ${ }^{15,23}$ In predisposed patients who fulfill the criteria, the diagnosis of $\mathrm{HH}$ can be assumed without liver biopsy. Nonetheless, the use of liver biopsy to demonstrate centrilobular necrosis may be necessary when the diagnosis is unclear, such as when aminotransferase levels are $<20$ times the upper limit of normal. ${ }^{14}$ Otherwise, biopsy is generally inadvisable in $\mathrm{HH}$ patients with multiple co-morbidities, especially those with coagulopathy.

\section{Table 1. Criteria for diagnosing hypoxic hepatitis*}

1. A clinical setting of cardiac, circulatory or respiratory failure

2. A dramatic, but transient, rise in serum aminotransferase activity

3. Exclusion of other causes of liver cell necrosis, especially viral or drug-induced hepatitis 
Table 2. Liver differential diagnosis for serum aminotransferase levels $>10$ times the upper limit of normal

Hypoxic hepatitis

Acute viral hepatitis

Toxin- or drug-induced liver injury

Autoimmune hepatitis

Liver trauma

Non-invasive imaging options like abdominal ultrasonography can be supportive in diagnosis of $\mathrm{HH}$. Dilation of the inferior vena cava and suprahepatic veins due to passive congestion is suggestive of $\mathrm{HH}^{46}$ However, the diagnostic utility of ultrasonography in $\mathrm{HH}$ has not yet been validated. Other imaging techniques, like computed tomography or magnetic resonance imaging, are not required for diagnosis but may help exclude other causes of liver injury. The specific pattern of lab test abnormalities can also help to exclude other diagnoses. For example, viral hepatitis typically has lower peaks in serum lactate dehydrogenase than does $\mathrm{HH}^{23}$ In addition, the pattern of liver injury in $\mathrm{HH}$ is hepatocellular rather than cholestatic, so large increases in alkaline phosphatase are atypical.

Specific measures of hepatic blood flow and function using non-invasive methods such as clearance of galactose or indocyanine green (ICG) have also been proposed to support diagnosis of $\mathrm{HH}$. Although galactose clearance has been used in previous studies to characterize hepatic blood flow, ${ }^{3,4}$ it has not been well-established clinically for diagnosis of $\mathrm{HH}$. Additionally, galactose is not solely cleared by the liver $^{47}$ and the clearance can be unpredictable in acute liver injury. ${ }^{48}$ ICG is more reliably cleared by hepatocytes, whereupon it enters bile circulation, and has been increasingly demonstrated as an accurate measure of hepatic function, even in cases of cirrhosis and $\mathrm{HH}^{49}$ ICG is a generally non-toxic, water soluble dye that binds tightly to plasma proteins; ${ }^{50}$ its plasma disappearance rate can be measured conveniently using the transcutaneous method of pulse densitometry. ${ }^{51}$ Given these advantages, there is increasing interest in ICG plasma disappearance rate as a diagnostic or even prognostic tool for $\mathrm{HH}_{;}{ }^{49,50}$ however, further studies are needed to firmly establish its clinical role. ${ }^{52}$ Finally, invasive hepatic hemodynamic monitoring, including measurement of hepatic venous pressure, can be used to evaluate the impact of congestive hepatopathy in acute liver injury, ${ }^{53}$ but presently it does not have a clearly defined role in $\mathrm{HH}$.

\section{Management}

The only established strategy for treating $\mathrm{HH}$ is to correct the underlying disease state. Prompt diagnosis and initiation of treatment is crucial, as delay in diagnosis has been shown to worsen mortality risk. ${ }^{5}$ Treatments directed at the predisposing condition include optimization of whole body circulation, maintenance of adequate mean arterial pressure, and preservation of liver microcirculation and oxygenation through the use of inotropes, vasodilators and diuretics. That being said, an ideal inotropic agent has not yet been identified, and the existing studies have reported only limited benefit in specific clinical circumstances. For example, dopamine may offer a survival benefit for patients with normotensive cardiogenic shock and kidney injury, ${ }^{54}$ and dobutamine has been proposed to augment splanchnic blood flow to the liver in patients with low cardiac index. ${ }^{55}$ The findings from these small studies are not widely generalizable, however.

Among the more experimental treatments, some have advocated for the use of $\mathrm{N}$-acetylcysteine or other antioxidants, but evidence is lacking that demonstrates their effectiveness. ${ }^{38}$ Another approach uses a modified dialysis system targeting substances bound to serum albumin, namely the molecular adsorbent recirculating system (MARS). It is theorized to remove small hydrophobic toxins that are normally detoxified by the healthy liver. While MARS showed some early promise in increasing liver circulation ${ }^{56}$ and providing survival benefit in acute liver failure, ${ }^{57}$ there is not yet sufficient evidence to recommend its regular use. Finally, it should be noted that liver transplantation is rarely indicated for the treatment of $\mathrm{HH} .{ }^{58}$

As $\mathrm{HH}$ is a consequence of cardiogenic, circulatory or respiratory failure, it often coincides with other organ system failures, including that of the lungs and kidneys. Specifically, the incidence of hepatopulmonary syndrome with $\mathrm{HH}$ has been shown to be as high as $46 \% .{ }^{59}$ In these instances, it is often difficult to determine whether the lung or kidney injury preceded the liver injury, or vice versa, but adequate management relies on determining the extent of multi-system failure. ${ }^{5}$ Additionally, glycemic control is paramount in managing $\mathrm{HH}$, as both hypoglycemia and hyperglycemia are possible. As in other forms of liver failure, a target blood glucose level of $<150 \mathrm{mg} / \mathrm{dL}$ is advisable. ${ }^{45}$

\section{Prognosis}

As a result of the life-threatening conditions underlying $\mathrm{HH}$, the prognosis is generally poor. The rates of in-hospital mortality from two large-pooled reviews were $56 \%$ and $59 \% .{ }^{7,8}$ Other reports put 1 -year survival at near $25 \% .^{3,4}$ The cause of death is usually not liver failure, however, but rather the predisposing condition. In a study of a large European cohort, the risk of inhospital mortality was found to be significantly greater among patients with higher peak levels of aspartate aminotransferase (mean: $5.129 \mathrm{U} / \mathrm{L}$ ), lactate dehydrogenase (mean: $5.047 \mathrm{U} / \mathrm{L}$ ), INR (mean: 2.9 ) and lactate (mean: $10.4 \mathrm{mmol} / \mathrm{L}$ ). ${ }^{5}$ In addition, prolonged durations of $\mathrm{HH}$ (defined as $>24$ hours of rising aspartate aminotransferase levels) were found to be associated with significantly poorer overall survival. ${ }^{5}$ Other biochemical and clinical abnormalities are associated with increased risk of inhospital mortality as well, including increased phosphate levels, encephalopathy, ${ }^{60}$ jaundice, ${ }^{40}$ and, in a recent prospective study, ICG plasma disappearance rate. ${ }^{49}$ The long-term outcome, however, is still largely determined by the overall cardiovascular morbidity and mortality. ${ }^{60}$

\section{Conclusions}

In ICU settings, $\mathrm{HH}$ is one of the most common and lethal causes of massively elevated serum aminotransferase levels. It usually results as a consequence of a severe underlying illness state, such as cardiac, circulatory or respiratory failure, leading to a rate of in-hospital mortality of $>50 \%$. Prompt recognition is vital, as delays in diagnosis and prolonged $\mathrm{HH}$ can worsen outcomes. The only recognized treatment is to correct the predisposing condition; the newest therapies directed at the liver still require further investigation before they can be widely recommended. 
Waseem N. et al: Hypoxic hepatitis

\section{Conflict of interest}

None

\section{Author contributions}

Jointly performed the manuscript writing (NW, PHC), critically revised the manuscript and administered the literature review $(\mathrm{PHC})$.

\section{References}

[1] Mallory FB. Necroses of the liver. J Med Res 1901;6:264-280.

[2] Bynum TE, Boitnott JK, Maddrey WC. Ischemic hepatitis. Dig Dis Sci 1979; 24:129-135. doi: 10.1007/BF01324740.

[3] Henrion J, Schapira M, Luwaert R, Colin L, Delannoy A, Heller FR. Hypoxic hepatitis: clinical and hemodynamic study in 142 consecutive cases. Medicine 2003;82:392-406. doi: 10.1097/01.md.0000101573.54295.bd.

[4] Birrer R, Takuda Y, Takara T. Hypoxic hepatopathy: pathophysiology and prognosis. Intern Med 2007;46:1063-1070. doi: 10.2169/internalmedicine.46. 0059 .

[5] Fuhrmann V, Kneidinger N, Herkner H, Heinz G, Nikfardjam M, Bojic A, et al. Hypoxic hepatitis: underlying conditions and risk factors for mortality in critically ill patients. Intensive Care Med 2009;35:1397-1405. doi: 10.1007/ s00134-009-1508-2.

[6] Raurich JM, Llompart-Pou JA, Ferreruela M, Colomar A, Molina M, Royo C, et al. Hypoxic hepatitis in critically ill patients: incidence, etiology and risk factors for mortality. J Anesth 2011;25:50-56. doi: 10.1007/s00540-0101058-3.

[7] Henrion J. Hypoxic hepatitis. Liver Int 2012;32:1039-1052. doi: 10.1111/j. 1478-3231.2011.02655.x.

[8] Tapper EB, Sengupta N, Bonder A. The incidence and outcomes of ischemic hepatitis: a systematic review with meta-analysis. Am J Med 2015;128: 1314-1321. doi: 10.1016/j.amjmed.2015.07.033.

[9] Pauwels A, Lévy VG. Ischemic hepatitis in cirrhosis: not so rare, not always lethal. J Clin Gastroenterol 1993;17:88-89. doi: 10.1097/00004836199307000-00024.

[10] Kamiyama T, Miyakawa H, Tajiri K, Marumo F, Sato C. Ischemic hepatitis in cirrhosis. clinical features and prognostic implications. J Clin Gastroenterol 1996;22:126-130. doi: 10.1097/00004836-199603000-00011.

[11] Rashed KA, McNabb WR, Lewis RR. Ischaemic hepatitis in the elderly. Gerontology 2002;48:245-249. doi: 10.1159/000058358.

[12] Fuchs S, Bogomolski-Yahalom V, Paltiel O, Ackerman Z. Ischemic hepatitis: clinical and laboratory observations of 34 patients. J Clin Gastroenterol 1998;26:183-186. doi: 10.1097/00004836-199804000-00007.

[13] Raman JS, Kochi K, Morimatsu H, Buxton B, Bellomo R. Severe ischemic early liver injury after cardiac surgery. Ann Thorac Surg 2002;74:16011606. doi: 10.1016/S0003-4975(02)03877-8.

[14] Henrion J, Schapira M, Heller FR. Ischemic hepatitis: the need for precise criteria. J Clin Gastroenterol 1996;23:305. doi: 10.1097/00004836199612000-00016.

[15] Giannini EG, Testa R, Savarino V. Liver enzyme alteration: a guide for clinicians. CMAJ 2005;172:367-379. doi: $10.1503 / \mathrm{cmaj} .1040752$.

[16] Whitehead MW, Hawkes ND, Hainsworth I, Kingham JG. A prospective study of the causes of notably raised aspartate aminotransferase of liver origin. Gut 1999;45:129-133. doi: 10.1136/gut.45.1.129.

[17] Fuhrmann V, Kneidinger N, Herkner H, Heinz G, Nikfardjam M, Bojic A, et al. Impact of hypoxic hepatitis on mortality in the intensive care unit. Intensive Care Med 2011;37:1302-1310. doi: 10.1007/s00134-011-2248-7.

[18] Chang JP, Tan CK. Serum albumin and male gender are independent predictors of mortality in patients with hypoxic hepatitis and can be used in a prognostic model to predict early in-patient mortality. Hepatology 2008; 48:447A-448A.

[19] Henrion J, Descamps O, Luwaert R, Schapira M, Parfonry A, Heller F. Hypoxic hepatitis in patients with cardiac failure: incidence in a coronary care unit and measurement of hepatic blood flow. J Hepatol 1994;21:696-703. doi: 10. 1016/S0168-8278(94)80226-2.

[20] Killip T 3rd, Payne MA. High serum transaminase activity in heart disease. Circulatory failure and hepatic necrosis. Circulation 1960;21:646-660. doi: 10.1161/01.CIR.21.5.646.

[21] Richman SM, Delman AJ, Grob D. Alterations in indices of liver function in congestive heart failure with particular reference to serum enzymes. Am J Med 1961;30:211-225. doi: 10.1016/0002-9343(61)90093-6.

[22] Seeto RK, Fenn B, Rockey DC. Ischemic hepatitis: clinical presentation and pathogenesis. Am J Med 2000;109:109-113. doi: 10.1016/S0002-9343(00) 00461-7.
[23] Trilok G, Qing YC, Li-Jun X. Hypoxic hepatitis: a challenging diagnosis. Hepatol Int 2012;6:663-669. doi: 10.1007/s12072-011-9336-1.

[24] Henrion J, Colin L, Schapira M, Heller FR. Hypoxic hepatitis caused by severe hypoxemia from obstructive sleep apnea. J Clin Gastroenterol 1997;24: 245-249. doi: 10.1097/00004836-199706000-00013.

[25] Blich M, Edelstein S, Mansano R, Edoute Y. Ischemic hepatitis induced by severe anemia. Isr Med Assoc J 2003;5:208-209.

[26] Molino G, Avagnina $P$, Ballarè M, Torchio M, Niro AG, Aurucci PE, et al. Combined evaluation of total and functional liver plasma flows and intrahepatic shunting. Dig Dis Sci 1991;36:1189-1196. doi: 10.1007/BF01307507.

[27] Reilly PM, Wilkins KB, Fuh KC, Haglund U, Bulkley GB. The mesenteric hemodynamic response to circulatory shock: an overview. Shock 2001;15: 329-343. doi: 10.1097/00024382-200115050-00001.

[28] Spapen H. Liver perfusion in sepsis, septic shock, and multiorgan failure. Anat Rec (Hoboken) 2008;291:714-720. doi: 10.1002/(ISSN)1932-8494.

[29] Lautt WW. Hepatic vasculature: a conceptual review. Gastroenterology 1977;73:1163-1169.

[30] Lautt WW. Mechanism and role of intrinsic regulation of hepatic arterial blood flow: hepatic arterial buffer response. Am J Physiol 1985;249:G549-G556.

[31] Henrion J, Minette P, Colin L, Schapira M, Delannoy A, Heller FR. Hypoxic hepatitis caused by acute exacerbation of chronic respiratory failure: a case-controlled, hemodynamic study of 17 consecutive cases. Hepatology 1999;29:427-433. doi: 10.1002/(ISSN)1527-3350.

[32] Ucgun I, Ozakyol A, Metintas M, Moral H, Orman A, Bal C, et al. Relationship between hypoxic hepatitis and cor pulmonale in patients treated in the respiratory ICU. Int J Clin Pract 2005;59:1295-1300. doi: 10.1111/j.17421241.2005.00609.x.

[33] Reinelt H, Radermacher P, Fischer G, Geisser W, Wachter U, Wiedeck H, et al. Effects of a dobutamine-induced increase in splanchnic blood flow on hepatic metabolic activity in patients with septic shock. Anesthesiology 1997;86: 818-824. doi: 10.1097/00000542-199704000-00012.

[34] Zhang $H$, Vincent JL. Oxygen extraction is altered by endotoxin during tamponade-induced stagnant hypoxia in the dog. Circ Shock 1993;40: $168-176$.

[35] Nelson DP, Samsel RW, Wood LD, Schumacker PT. Pathological supply dependence of systemic and intestinal $\mathrm{O} 2$ uptake during endotoxemia. J Appl Physiol (1985) 1988;64:2410-2419.

[36] Jaeschke $H$. Kupffer cell-induced oxidant stress during hepatic ischemiareperfusion: does the controversy continue? Hepatology 1999;30:15271528. doi: 10.1002/(ISSN)1527-3350.

[37] Adkison D, Höllwarth ME, Benoit JN, Parks DA, McCord JM, Granger DN. Role of free radicals in ischemia-reperfusion injury to the liver. Acta Physiol Scand Suppl 1986;548:101-107.

[38] Fuhrmann V, Jäger B, Zubkova A, Drolz A. Hypoxic hepatitis - epidemiology, pathophysiology and clinical management. Wien Klin Wochenschr 2010;122: 129-139. doi: 10.1007/s00508-010-1357-6.

[39] Myers RP, Cerini R, Sayegh R, Moreau R, Degott C, Lebrec D, et al. Cardiac hepatopathy: clinical, hemodynamic, and histologic characteristics and correlations. Hepatology 2003;37:393-400. doi: 10.1053/jhep.2003.50062.

[40] Jäger B, Drolz A, Michl B, Schellongowski P, Bojic A, Nikfardjam M, et al. Jaundice increases the rate of complications and one-year mortality in patients with hypoxic hepatitis. Hepatology 2012;56:2297-2304. doi: 10.1002/ hep. 25896.

[41] Fuhrmann V, Drolz A, Kneidinger N, Schenk P. Hyperammonemia in patients with hypoxic hepatitis. Gut 2009;58:P0450.

[42] Gitlin N, Serio KM. Ischemic hepatitis: widening horizons. Am J Gastroenterol $1992 ; 87: 831-836$

[43] Cassidy WM, Reynolds TB. Serum lactic dehydrogenase in the differential diagnosis of acute hepatocellular injury. J Clin Gastroenterol 1994;19: 118-121. doi: 10.1097/00004836-199409000-00008.

[44] De Jonghe B, Cheval C, Misset B, Timsit JF, Garrouste M, Montuclard L, et al. Relationship between blood lactate and early hepatic dysfunction in acute circulatory failure. J Crit Care 1999;14:7-11. doi: 10.1016/S0883-9441 (99)90002-3.

[45] Stravitz RT, Kramer AH, Davern T, Shaikh AO, Caldwell SH, Mehta RL, et al. Intensive care of patients with acute liver failure: recommendations of the U.S. Acute Liver Failure Study Group. Crit Care Med 2007;35:2498-2508. doi: 10.1097/01.CCM.0000287592.94554.5F.

[46] Denis C, De Kerguennec C, Bernuau J, Beauvais F, Cohen Solal A. Acute hypoxic hepatitis ('liver shock'): still a frequently overlooked cardiological diagnosis. Eur J Heart Fail 2004;6:561-565. doi: 10.1016/j.ejheart.2003. 12.008 .

[47] Keiding S. Galactose clearance measurements and liver blood flow. Gastroenterology 1988;94:477-481. doi: 10.1016/0016-5085(88)90440-4.

[48] Henderson JM, Kutner MH, Bain RP. First-order clearance of plasma galactose: the effect of liver disease. Gastroenterology 1982;83:1090-1096.

[49] Horvatits T, Kneidinger N, Drolz A, Roedl K, Rutter K, Kluge S, et al. Prognostic impact of ICG-PDR in patients with hypoxic hepatitis. Ann Intensive Care 2015;5:47. doi: 10.1186/s13613-015-0092-6. 
[50] Halle BM, Poulsen TD, Pedersen HP. Indocyanine green plasma disappearance rate as dynamic liver function test in critically ill patients. Acta Anaesthesiol Scand 2014;58:1214-1219. doi: 10.1111/aas.12406.

[51] Reekers M, Simon MJ, Boer F, Mooren RA, van Kleef JW, Dahan A, et al. Pulse dye densitometry and indocynaine green plasma disappearance in ASA physical status I-II patients. Anesth Analg 2010;110:466-472. doi: 10.1213/ ANE.0b013e3181c92b09.

[52] Vos J], Wietasch JK, Absalom AR, Hendriks HG, Scheeren TW. Green light for liver function monitoring using indocyanine green? An overview of current clinical applications. Anaesthesia 2014;69:1364-1376. doi: 10.1111/anae. 12755.

[53] Myers RP, Cerini R, Sayegh R, Moreau R, Degott C, Lebrec D, et al. Cardiac hepatopathy: clinical, hemodynamic, and histologic characteristics and correlations. Hepatology 2003;37:393-400. doi: 10.1053/jhep.2003.50062.

[54] Naschitz JE, Yeshurun D. Compensated cardiogenic shock: a subset with damage limited to liver and kidneys. The possible salutary effect of lowdose dopamine. Cardiology 1987;74:212-218. doi: 10.1159/000174199.
[55] Kram HB, Evans T, Bundage B, Shoemaker WC. Use of dobutamine for treatment of shock liver syndrome. Crit Care Med 1988;16:644-645. doi: 10.1097/00003246-198806000-00017.

[56] Stefoni S, Coli L, Bolondi L, Donati G, Ruggeri G, Feliciangeli G, et al. Molecular adsorbent recirculating system (MARS) application in liver failure: clinical and hemodepurative results in 22 patients. Int $\mathrm{J}$ Artif Organs 2006;29:207-218.

[57] El Banayosy A, Kizner L, Scheuler V, Bergmeier S, Cobaugh D, Koerfer R. First use of the molecular adsorbent recirculating system technique on patients with hypoxic liver failure after cardiogenic shock. ASAIO J 2004;50:332-337.

[58] Polson J, Lee WM. AASLD position paper: The management of acute liver failure. Hepatology 2005;41:1179-1197, doi: 10.1002/(ISSN)1527-3350.

[59] Fuhrmann V, Madl C, Mueller C, Holzinger U, Kitzberger R, Funk GC, et al. Hepatopulmonary syndrome in patients with hypoxic hepatitis. Gastroenterology 2006;131:69-75. doi: 10.1053/j.gastro.2006.04.014.

[60] Taylor RM, Tujios S, Jinjuvadia K, Davern T, Shaikh OS, Han S, et al. Short and long-term outcomes in patients with acute liver failure due to ischemic hepatitis. Dig Dis Sci 2012;57:777-785. doi: 10.1007/s10620-011-1918-1. 